\title{
Research on Multi-period Stochastic Inventory Model of Tobacco Commercial Enterprise
}

\author{
Dongbing Huang, Dandan Zhang \\ Department of technology economy and management, Finance and economics University, Guizhou, 550025, China
}

\begin{abstract}
Build multi-period stochastic inventory model of tobacco commercial enterprise and determine optimal inventory stock and order point under maximum expected profit. Case studies have shown that this model can optimize tobacco commercial enterprise inventory, so as to achieve the effect of inventory cost optimization.
\end{abstract}

Keywords-multi-period; stochastic inventory model; tobacco commercial enterprise; order quantity.

\section{INTRODUCTION}

Inventory is important current asset of an enterprise. Scientific and effective inventory management can reduce the average capital takes up level of an enterprise to enable an increase of inventory flow rate and total asset turnover, thereby improving enterprise economic benefits. As we all know, tobacco commercial enterprise, as a significant source of national and local fiscal levy, plays an important role in national economy. However, inventory cost accounts for a large part in tobacco commercial enterprise cost. Therefore, a good control of inventory costs can not only reduce total cost of an enterprise, but also speed up its turnover, so as to improve economic benefits. In cycle inventory control model, most tobacco commercial enterprises basically adopt $\mathrm{ABC}$ classification and economic order quantity to manage inventory etc. This paper will build multi-period stochastic inventory model of tobacco commercial enterprise and determine optimal inventory stock and order point under maximum expected profit, so as to achieve the effect of inventory cost optimization.

\section{INVENTORY COST OPTIMIZATION OF TOBACCO COMMERCIAL ENTERPRISE}

\section{A. Inventory cost structure}

Inventory cost refers to costs produced in the process of product order, purchase, storing, storage and out-storage as well as losses probably caused by products shortage. It mainly include the following four types: ordering cost, cost of goods, storing cost and shortage cost [1].

i) Ordering Cost

Ordering cost refers to expenses incurred in product purchase. The formula is as follows:

$$
\mathrm{TCP}=\mathrm{N} \times \mathrm{CP}=\frac{\frac{D}{Q}}{\times \mathrm{CP}}
$$

Note: TCP: total order cost, $\mathrm{N}$ : order time in certain period, CP: ordering cost of each time, D: demand quantity, Q: order quantity.

ii) Cost of Goods

Cost of goods refers to product expenses, the formula can be expressed as follows:

$$
\mathrm{TCr}=\mathrm{X} \times \mathrm{Cr}
$$

Note: TCr: cost of goods, X: demand quantity of goods, Cr: buying rate.

iii) Storing Cost

Storing cost is the fee produced in good storage, that is to say, the fee caused in the process of inventory to the dispatch of goods. The formula is:

$$
\mathrm{TCH}=\frac{\frac{Q}{2}}{\times \mathrm{CH}}
$$

Among them, TCH refers to storage cost, Q is quantity of goods, and $\mathrm{CH}$ refers to storage rate.

iv) Shortage Cost

It'S sure that shortage cost is higher than cost of goods.

\section{B. Purpose and content of inventory optimization}

Main content of inventory optimization is to determine inventory quantity, order point and quantity of an enterprise according to its management purpose and market demand situation as well. The goal of inventory optimization is, on the one hand, to reduce inventory cost, on the other hand, to meet customer needs. As a matter of fact, there are contradictions between them. Hence it is necessary to seek the best point of balance, so as to achieve the goal of inventory optimization.

\section{INFINITE MULTI-PERIOD STOCHASTIC INVENTORY MODEL}

\section{A. Model description and assumptions}

Multi-period is point to long-term and repeated demand for inventory and inventory supplement is always needed, Operating period of tobacco commercial enterprise belongs to multi-period mode and it is infinite. which is the essential difference between single-cycle (markdown sale of ending inventory). Because demand of retail user is random, thus random demand variable is adopted.

Assume that each cycle has the same cost structure. Then choosing one certain cycle as investigation object, the costs can be assumed as following:

i) Ordering cost, k; 
ii) Unit cost of cigarette, $K$;

iii) Unit cost of cigarette, $\mathrm{p}$;

iv) Inventory cost of unit h;

v) Shortage cost of unit cigarette, $b$;

vi) Last ending inventory, I; Begining ordering quantity, $\mathrm{Q}$; minimum inventory quantity after purchases or begining inventory, $\mathrm{R}, \mathrm{R}=\mathrm{I}+\mathrm{Q}$.

\section{B. Model establishment}

Assuming that cigarette demand of this period is $\mathrm{X}$, when $\mathrm{X}$ is smaller or equal to $\mathrm{R}$, all demand can be achieved. If $X$ products are sold at the wholesale price $\mathrm{P}$ Yuan and the rest of $(\mathrm{R}-\mathrm{X})$ goods are taken as the beginning inventory, then storage cost of this period should be $\frac{[R-(R-X)]}{2} h$ or $\frac{X}{2} h$. Supposing that storage cost of goods that have been already sold is out of consideration, expected profit by this time should be:

$$
\mathrm{E}[\mathrm{W} 1(\mathrm{R})]=\sum_{X=0}^{R}\left[p X-\frac{X}{2} h-k-K(R-I)\right] P(X)
$$

When $\mathrm{X}$ is larger than $\mathrm{R}$, cigarette demand quantity is greater than maximum inventory, all $\mathrm{R}$ are sold at unit price $\mathrm{p}$, and demand of $(\mathrm{X}-\mathrm{R})$ has not been reached, then shortage cost $\mathrm{b}(\mathrm{X}-\mathrm{R})$ is produced. The corresponding expected profit is:

$$
\begin{aligned}
& \qquad \sum_{X=R+1}^{\infty}[p R-b(X-R)-k-K(R-I)] P(X) \\
& \text { Thus, total expected profit model is [2] }
\end{aligned}
$$

$\mathrm{E}[\mathrm{W}(\mathrm{R})]=\mathrm{E}[\mathrm{W} 1(\mathrm{R})]+\mathrm{E}[\mathrm{W} 2(\mathrm{R})]$

$$
\mathrm{E}[\mathrm{W}(\mathrm{R})]=\sum_{X=0}^{R}\left[p X-\frac{X}{2} h\right] P(X)+\sum_{X=R+1}^{\infty}[p R-b(X-R)] P(X)-k-K(R-I)
$$

Now, to maximize total expected profit, the best or biggest value of $\mathrm{R}$ should be determined. If $\mathrm{X}$ is a discrete value, marginal analysis method is required for solving this problem. If there is a best $\mathrm{R}$, the following two inequalities should be satisfied at the same time:

$$
\begin{aligned}
\mathrm{E}[\mathrm{W}(\mathrm{R})] & \geq \mathrm{E}[\mathrm{W}(\mathrm{R}+1)] \\
\mathrm{E}[\mathrm{W}(\mathrm{R})] & \geq \mathrm{E}[\mathrm{W}(\mathrm{R}-1)]
\end{aligned}
$$

The best or biggest inventory quantity can be gotten by the following inequality:

$$
\sum_{X=0}^{R-1} P(X) \leq N \leq \sum_{X=0}^{R} P(X)
$$

In formula (2), critical value $\mathrm{N}$ is

$$
\mathrm{N}=\frac{p+b-K}{p+b+h}
$$

The above model is only suitable for business enterprises, that is, the situation of order being directly used for sales. But the above model can also apply to continuous demand variable. If random variable $\mathrm{D}$ is continuous, its density function is $\mathrm{f}(\mathrm{x})$ and distribution function is
$\mathrm{F}(\mathrm{X})=\mathrm{P}(\mathrm{D} \leq \mathrm{X})=\int_{0}^{x} f(x) d x \quad$.Substitute integral for summation, differential for difference and $f(x) d x$ for $\mathrm{P}(\mathrm{X})$, then models corresponding to formula (1) and (2) are respectively as following:

$\mathrm{E}\left[\mathrm{W}(\mathrm{R})=\int_{0}^{R}\left[p x-\frac{x}{2} h\right] f(x) d x+\int_{R}^{\infty}[p R-b(x-R)] f(x) d x-k-K(R-I)\right.$

$$
\int_{0}^{R} f(x) d x=\frac{p+b-K}{p+b+h}
$$

\section{Determination of order point}

Supposing beginning inventory to be I and the demand is random, then order may be determined by the value of I after $\mathrm{R}$ is calculated. If order is not needed, $\mathrm{k}$ Yuan ordering fee will be saved. If $I$ is near to $R$, order may be not economic.

Next, compare total expected profit (or total expected cost) in the situation of ordering with ordering free. If order is not needed, total expected profit of this period (including beginning inventory cost, KI) should be:

$$
\mathrm{E}[\mathrm{W}(\mathrm{I})]=\sum_{X=0}^{I}\left[p X-\frac{[I-(I-X)]}{2} h\right] P(X)+\sum_{X=I+1}^{\infty}[p I-b(X-I)] P(X)-K I
$$

If an order is needed, total expected profit of this period (including beginning inventory cost, $\mathrm{KI}$ ) should be:

$$
\begin{aligned}
& \mathrm{E}[\mathrm{W}(\mathrm{R})]=\sum_{X=0}^{R}\left[p X-\frac{X}{2} h\right] P(X)+\sum_{X=R+1}^{\infty}[p R-b(X-R)] P(X)-k-K R \\
& \text { If } \mathrm{E}[\mathrm{W}(\mathrm{I})] \geq \mathrm{E}[\mathrm{W}(\mathrm{R})] \text {, ordering free is economic, namely }
\end{aligned}
$$
[7]

$$
\begin{gathered}
\sum_{X=0}^{I}\left[p X-\frac{[I-(I-X)]}{2} h\right] P(X)+\sum_{X=I+1}^{\infty}[p I-b(X-I)] P(X)-K I \\
\geq \sum_{X=0}^{R}\left[p X-\frac{X}{2} h\right] P(X)+\sum_{X=R+1}^{\infty}[p R-b(X-R)] P(X)-k-K R
\end{gathered}
$$

When $I$ is equal to $R$, the inequality can be established and there must be a solution. When $\mathrm{I}$ is smaller than $\mathrm{R}$, storage cost on the left side of inequality is established to the one on the right, meanwhile, shortage cost on left of inequality is greater than the one on the right, still the inequality can be established. If I with more than one values can make formula (7) established, then minimum value can be determined as order point $r$. Therefore, as for beginning check inventory I, if I $<\mathrm{r}$, then make an order and purchase quantity should be $\mathrm{Q}, \mathrm{Q}=\mathrm{R}$ - I; if $\mathrm{I} \geq \mathrm{r}$, then order is not needed in this period.

\section{EXAMPLE ANALYSIS}

The central task of tobacco commercial enterprises is to meet market demand of cigarettes, ensuring that cigarette supply will be not out of stock or sold out. A set of data about the storage and sale of certain brand cigarette belongs to a tobacco company in 2013 is shown below: 
TABLE I. STORAGE AND SALE LIST OF CERTAIN BRAND CIGARETTE UNIT: BOX

\begin{tabular}{|l|l|l|l|}
\hline Time & $\begin{array}{l}\text { Beginning } \\
\text { Inventory }\end{array}$ & $\begin{array}{l}\text { Sale } \\
\text { Quantity }\end{array}$ & $\begin{array}{l}\text { Ending } \\
\text { Inventory }\end{array}$ \\
\hline January & 1830 & 4487 & 3343 \\
\hline February & 3343 & 1456 & 2537 \\
\hline March & 2537 & 2145 & 891 \\
\hline April & 891 & 1946 & 1245 \\
\hline May & 1245 & 2153 & 1192 \\
\hline June & 1192 & 1330 & 1302 \\
\hline July & 1302 & 1376 & 2546 \\
\hline August & 2546 & 972 & 1574 \\
\hline September & 1574 & 1563 & 1010 \\
\hline October & 1010 & 896 & 1115 \\
\hline November & 1115 & 1298 & 1217 \\
\hline December & 1217 & 512 & 3774 \\
\hline $\begin{array}{l}\text { Amount } \\
\text { total in }\end{array}$ & 19802 & 20134 & 21746 \\
\hline
\end{tabular}

For this brand cigarette, the trarnsfer price (excluding tax) is 8885 Yuan/box and the uniform wholesale price is 11538 Yuan/box. In addition, of each box, the storage cost is equal to 66.05 Yuan/box. Ordering cost: 263 Yuan/ time. Besides shortage cost should be higher than goods cost and assumed to be $8886 \mathrm{Yuan} / \mathrm{box}$. The running cycle is infinite and daily demand is continuous random variable, hence the density function is:

$$
f(x)= \begin{cases}\frac{1}{3975} & 512 \leq x \leq 4487 \\ 0 & \text { else }\end{cases}
$$

Solution analysis: taking monthly period, $\mathrm{p}=11538$ Yuan/box, $\mathrm{k}=263$ Yuan/time, $\mathrm{k}=8885$ Yuan/box, $\mathrm{b}=$ 8886 Yuan/box, $\mathrm{h}=66.05 \mathrm{Yuan} / \mathrm{box}$. The result achieved by formula (4)

$$
\int_{512}^{R} \frac{1}{3975} d x=0.56
$$$$
\mathrm{R}=2738
$$

The quantity of maximum inventory is 2738 boxes.

When the demand is continuous random variable, formula (5) should be

$$
\begin{gathered}
\int_{0}^{I}\left[p x-\frac{[I-(I-x)]}{2} h\right] f(x) d x+\int_{I}^{\infty}[p I-b(x-I)] f(x) d x-K I \geq \\
\int_{0}^{R}\left[p x-\frac{x}{2} h\right] f(x) d x+\int_{R}^{\infty}[p R-b(x-R)] f(x) d x-k-K R
\end{gathered}
$$

The ringht quantity $=$

$\int_{512}^{2738}\left[11538 x-66.05\left(\frac{x}{2}\right)\right] \frac{d x}{3975}+$

$\int_{2738}^{4487}[11538 \times 2738-8886(x-2738)] \frac{d x}{3975}-263-8885 \times 2738$

$=-3431558.53$

The left quantity $=$

$\int_{512}^{I}\left[11538 x-66.05\left(\frac{I-(I-x)}{2}\right)\right] \frac{d x}{3975}+\int_{I}^{4487}[11538 I-8886(x-I)] \frac{d x}{3975}-8885 I$

$=-2.57 \mathrm{I} 2+14157.86 \mathrm{I}-22927947.36$

So, $-2.57 \mathrm{I} 2+14157.86 \mathrm{I}-22927947.36 \geq-3431558.53$

$-2.57 \mathrm{I} 2+14157.86 \mathrm{I}-19496388.83 \geq 0$

$2.57 \mathrm{I} 2-14157.86 \mathrm{I}+19496388.83 \leq 0$

End, $2725.51 \leq \mathrm{I} \leq 2783.38$

So, $\mathrm{r}=2725.51$

So, beginning check inventory levels of each month is represented by the letter I. If I is less than 2725.51 boxes, stock supplement is allowed and purchase quantity should be $(2738-\mathrm{I})$, otherwise, it is not economic to buy more goods.

\section{V.CONCLUSIONS}

Determine whether a stock supplement is economic or not by examining the level of beginning inventory. After an analysis of all variables and final inventory quantity, we know that any change of demand quantity, order quantity, shortage cost and storage cost will have an effect on maximum inventory quantity. In addition, demand changes of retail clients as well as terminal consumers also have a significant effect on inventory. Therefore, it is necessary to reduce the uncertainty of demand and reasonably control all costs in inventory management. Taking tobacco commercial enterprise as an object, calculate the maximum inventory quantity of cigarette, optimal order point and quantity with infinitely multi-period stochastic inventory model under the condition of demand uncertainty.

\section{REFERENCES}

[1] Sunil Chopra, Peter Meinl.Supply Chain Mangment-Strategy, Planning and Operations Beijing: Social Sciences Academic Press.2003: 181-184

[2] Chen, F. Optimal policies for multi-echelon inventory problems with batch ordering [J]. Operations Research, 2000(3): 376-389 